\title{
Health Information Systems
}

\section{New Shifts and Emerging Trends in Health IT Infrastructures}

\author{
C. Bréant, Section Editor for the IMIA Yearbook Section on Health Information Systems \\ Department of Imaging and Medical Informatics, Geneva University Hospitals, Geneva, Switzerland
}

\section{Introduction}

The field of health information systems is driving active research and development works that continue to span many areas of studies; for instance, the onset of personal health records (PHRs), the exploration of solutions to contain the worrying rising costs of health care, and the modelling and assessment of the efficiency of clinical information systems.

\section{New Trends in Health IT}

Last year's trends and corresponding yearbook selection have chiefly been on a) the assessment of the quality of information processing in hospitals, b) new architectures to federate many health care centers, and c) on two original works consisting in the use of IT in a developing country to tackle health problems and the development of an open source PACS [1].

This year's selection reflects emerging trends in health IT infrastructures and data management which draw a lot of interest among peers but also many interrogations.

PHR systems are usually available through the internet/Web and enable patients to create, review, or annotate records related to any aspect of their health condition. A PHR is controlled by the individual and can be shared with care providers or family members. Consequently, the wide use of PHRs will trigger a main shift in the management of health information with patients directly empowered with the monitoring and distribution of their own data [2,3].
It's worth noting as well that companies developing PHRs, mostly originating from the dot-com and internet world, will manage and host patient health data in place of traditional health institutions [2]. Though, PHRs are still in an early state of development and adoption, with the promise of better care, improved communication with the care providers, and reduced costs [2].

Information technology (IT) in hospitals has the potential to reduce and/ or avoid medical errors, and improve patient care. Nevertheless, with the rising costs of health care, IT is under scrutiny and economical pressure $[4,5]$. Many hospitals, whether of small size in rural regions of industrialized nations or in developing countries, cannot afford the latest IT infrastructure and strive to take advantage of IT systems at moderate costs. Hence, hospital to hospital IT outsourcing partnership is an innovative response to this issue that can potentially benefit both the outsourcing smaller sized rural hospitals and the outsourced large and well equipped hospital [4]. Open source software and Web based health information are other technologies that will be further explored given their intrinsic lower costs $[6,7,8]$.

The modelling of clinical information system in various aspects; security, decision, support, and mobile e-health $[9,10,11,12]$ is tackled by many papers. Main objectives are to identify pitfalls and areas of improvement. In parallel, the evaluation of systems is an important topic in order to gauge and measure the "return" value of existing systems $[13,14,15,16]$.

Prototyping of sophisticated systems for the wireless monitoring of patients 
health condition is still generating a lot of interest in our ever increasing need for novel and innovative solutions $[17,18]$.

\section{Conclusions}

The result of the selection process for this 2009 yearbook section on health information systems includes five papers as listed in Table 1. A short content summary of these selected papers can be found in the Appendix of this synopsis.

A recent shift in the patient information management, introduced by personally controlled health record (PCHR) systems is analyzed in [2]. Opportunities and challenges are examined as well as key issues for clinical research. In [3], the authors describe and compare challenges and lessons learned by the implementation of three PCHRs developed in different settings. A study outlining the benefits and challenges of hospital to hospital partnerships in developing IT infrastructure is presented in [4]. For the first time, a comparison of the use of IT in hospitals from seven industrialized nations has been made and results are discussed in [16]. Finally a fifth paper gives a comprehensive description of the design, building, use and evaluation of a wireless prototype to monitor ambulatory patients, which can be useful in overcrowded emergency departments or at disaster scenes [17].

\section{Acknowledgement}

I greatly acknowledge the support of Martina Hutter and of the reviewers in the selection process of the IMIA Yearbook.

\section{References}

1. Geissbuhler A, Kulikowski C, editors. IMIA Yearbook of Medical Informatics 2008. Methods Inf Med 2008;47 Suppl 1:52-4.

2. Mandl KD, Kohane IS, Tectonic shifts in the health information economy. N Engl J Med 2008 Apr 17:358(16):1732-7.

3. Halamka JD, Mandl KD, Tang PC. Early experi-

Table I Best paper selection of articles for the IMIA Yearbook of Medical Informatics 2009 in the section 'Health Information Systems'. The articles are listed in alphabetical order of the first author's surname.

\section{Section}

Health Information Systems

- Curtis DW, Pino EJ, Bailey JM, Shih El, Waterman J, Vinterbo SA, Stair TO, Guttag JV, Greenes RA, Ohno-Machado L. SMART-an integrated wireless system for monitoring unattended patients. J Am Med Inform Assoc 2008 Jan-Feb; 15(1):44-53.

- Halamka JD, Mandl KD, Tang PC. Early experiences with personal health records. J Am Med Inform Assoc 2008 JanFeb;15(1):1-7.

- Jha AK, Doolan D, Grandt D, Scott T, Bates DW. The use of health information technology in seven nations. Int J Med Inform 2008 Dec;77(12):848-54.

- Mandl KD, Kohane IS. Tectonic shifts in the health information economy. N Engl J Med 2008 Apr 17;358(16):1732-7.

- Reddy MC, Purao S, Kelly M. Developing IT Infrastructure for Rural Hospitals: A Case Study of Benefits and Challenges of Hospital-to-Hospital Partnerships. J Am Med Inform Assoc 2008 Jul-Aug; 15(4):554-8.

ences with personal health records. J Am Med Inform Assoc.2008 Jan-Feb;15(1):1-7.

4. Reddy MC, Purao S, Kelly M. Developing IT Infrastructure for Rural Hospitals: A Case Study of Benefits and Challenges of Hospital-to-Hospital Partnerships. J Am Med Inform Assoc 2008 JulAug;15(4):554-8.

5. Hurlen P, Ostbye T, Borthne A, Gulbrandsen P. Introducing PACS to the Late Majority. A Longitudinal Study. J Digit Imaging 2008 Nov 1.

6. Callen JL, Buyankhishig B, McIntosh JH. Clinical information sources used by hospital doctors in Mongolia. Int J Med Inform 2008 Apr;77(4):249-55.

7. Ma J, Otten M, Kamadjeu R, Mir R, Rosencrans L, McLaughlin S, Yoon S. New frontiers for health information systems using Epi Info in developing countries: structured application framework for Epi Info (SAFE). Int J Med Inform 2008 Apr;77(4):219-25.

8. Vanmeulebrouk B, Rivett U, Ricketts A, Loudon M. Open source GIS for HIV/AIDS management. Int J Health Geogr 2008 Oct 22; 7:53.

9. Winter A, Strübing A. Model-based Assessment of Data Availability in Health Information Systems. Methods Inf Med 2008;47(5):417-24.

10. Jürjens J, Rumm R. Model-based Security Analysis of the German Health Card Architecture. Methods Inf Med 2008; 47(5):409-16.

11. Mathe J, Werner J, Lee Y, Malin B, Ledeczi A. Model-based design of clinical information systems. Methods Inf Med 2008;47(5):399-408.

12. Ray P, Parameswaran N, Chan V,Yu W. Awareness modelling in collaborative mobile e-health. J Telemed Telecare 2008;14(7):381-5.

13. Kawasumi Y, Tamblyn R, Platt R, Ernst P, Abrahamowicz M, Taylor L. Evaluation of the use of an integrated drug information system by primary care physicians for vulnerable population. Int J Med Inform 2008 Feb;77(2):98-106.

14. Bakken S, Currie LM, Lee NJ, Roberts WD, Collins $\mathrm{SA}$, Cimino JJ. Integrating evidence into clinical information systems for nursing decision support. Int J Med Inform 2008 Jun;77(6):413-20.
15. Garrib A, Stoops N, McKenzie A, Dlamini L, Govender T, Rohde J, et al. An evaluation of the District Health Information System in rural South Africa. S Afr Med J 2008 Jul;98(7):549-52.

16. Jha AK, Doolan D, Grandt D, Scott T, Bates DW. The use of health information technology in seven nations. Int J Med Inform 2008 Dec;77(12):848-54.

17. Curtis DW, Pino EJ, Bailey JM, Shih EI, Waterman J, Vinterbo SA, et al. SMART - an integrated wireless system for monitoring unattended patients. J Am Med Inform Assoc 2008 Jan-Feb;15(1):44-53.

18. Rojas-Barahona LM, Giorgino T. Adaptable dialog architecture and runtime engine (AdaRTE): A framework for rapid prototyping of health dialog systems. Int J Med Inform 2008 Sep 15.

\section{Correspondence to:}

Claudine Bréant, PhD

Department of Imaging and Medical Informatics

Geneva University Hospitals

Rue Gabrielle-Perret-Gentil, 4

1211 Geneva, Switzerland

Tel: +41223726179

Fax: +41223728879

E-mail: claudine.breant@sim.hcuge.ch 
Appendix: Content Summaries of Selected Best Papers for the IMIA Yearbook 2009, Section Health Information Systems*

\author{
Curtis DW, Pino EJ, Bailey JM, Shih El, \\ Waterman J, Vinterbo SA, Stair TO, Guttag \\ JV, Greenes RA, Ohno-Machado L \\ SMART - an integrated wireless system for \\ monitoring unattended patients
}

J Am Med Inform Assoc 2008 JanFeb;15(1):44-53

This technical and comprehensive paper describes the design, building, use, and evaluation of the Smart system, a continuous monitoring system for both over crowded emergency rooms and disaster sites. These are settings where patients cannot be well monitored after triage and where patient may deteriorate suddenly without being noticed which is the case in places where patients outnumber caregivers. The Smart system is different from other similar systems in that it could be part of a regular emergency department and at the same time it could easily extend to field work when necessary. Several existing similar systems are described and differences with the Smart system design and objectives are outlined. The paper gives a detailed description of the design and implementation of the various modules of the system. The Smart Central includes a decision support program that analyses data and triggers the alarms. The caregiver module proposes two interfaces, one associated with the Smart Control and one for the caregiver PDA. A thorough description of the operating modes of the system is presented. An initial evalua-

\footnotetext{
* The complete papers can be accessed in the Yearbook's full electronic version, provided that permission has been granted by the copyright holder(s).
}

tion at Brigham and Women's Hospital's Emergency Department in Boston with 145 post-triage patients is presented and discussed.

\section{Halamka JD, Mandl KD, Tang PC Early experiences with personal health records J Am Med Inform Assoc 2008 Jan- Feb;15(1):1-7}

Personal Health Records (PHRs) give patients web based access to their own healthcare data and enable them to be stewards of their own information. This paper presents three case studies of such systems: 1) PAMFOnline at Palo Alto Medical Foundation (a clinic version of MyChart, a patient portal of a commercialized EHR), 2) PatientSite developed by and hosted at the Beth Israel Deaconess Medical Center which allows patients to amend their own record on-line, and 3) Indivo at Children's Hospital Boston. Indivo, an open source system, results from a research grant initiative. It is a container to integrate copies of data from diverse hospital EMRs and to maintain collated copies of records. Implementation challenges from 1999 to 2007 are described and future goals for the next five years are discussed. The authors share their collective experiences and lessons learned from operating PHRs in their respective institutions: a community based multi-specialty group practice, a university hospital, and a children's hospital. The experience at these three institutions demonstrates that personal health records which share data among patients and providers can successfully be deployed but requires careful attention regarding issues such as privacy, security, data stewardship, and personal control.

\section{Jha AK, Doolan D, Grandt D, Scott T, Bates DW The use of health information technology in} seven nations

Int J Med Inform 2008, Int J Med Inform $2008 \mathrm{Dec} ; 77(12): 848-54$

The purpose of this paper is to determine and compare the adoption and use of health information technology and more specifically electronic health records (EHR) and health information exchange (HIE) in seven industrialized nations (United States, Canada, United Kingdom, Germany, Netherlands, Australia, and New Zealand). This study was motivated by the fact that despite high levels of spending in these nations, there is still the necessity to improve the quality and efficiency of care. Also it is also expected by the authors that the results of this study could give some insights on how the United States could improve the adoption of EHRs. Data is collected through a combination of publications and interviews with experts from all seven countries. The situation is compared according three topics: the EHR rate of use in the ambulatory and hospital setting, the adoption of health information exchange technology, and the role of the public sector in promoting the utilization of health information technology. Results are presented for these three topics regarding the situation for each country reflecting both similarities and striking differences. The authors observe that hospitals across the seven countries part of the study have been slow to adopt EHRs, which are still in an early stage of development. They also remark that the benefits of HIE will be obtained only at the cost of significant financial investments.

\section{Mandl KD, Kohane IS \\ Tectonic shifts in the health information economy}

N Engl J Med 2008 Apr 17;358(16):1732-7

This viewpoint paper discusses on the major changes in health information systems which just started in the last few years with the increasingly adoption of personally controlled health records (PCHRs) systems. PCHRs are computer platforms that enable patients to personally manage their own health care records. The authors discuss both on the new business opportunities sought by large corporations in the 
management of health care information and on the efficiency and cost saving issues brought by these systems. Moreover, the authors stress that the PCHR platform model introduces a shift in the control of health information previously ensured by each care provider institution. While this will provide assistance with clinical care processes, it will affect the biomedical research enterprise as well. A new scale of data 'liquidity' into PCHR platforms will be expected where health care consumers independently decide about subsequent disclosure of their data. As a result, companies new to health care may ultimately house and manage the most comprehensive and up-to-date health care databases. The authors fear that the access to the best research resources will be affected in ways that cannot be fully predicted. The conclusion ends with hope that under favorable conditions, consumers with PCHRs will soon control their health care data making health care safer and biomedical research more efficient.

\section{Reddy MC, Purao S, Kelly M}

Developing IT Infrastructure for Rural Hospitals: A Case Study of Benefits and Challenges of Hospital-to-Hospital Partnerships

\section{J Am Med Inform Assoc 2008 Jul-Aug; 15(4):554-8}

This paper presents a study examining benefits and challenges for smaller size hospitals in outsourcing IT infrastructure from a larger and more technologically advanced hospital in their region. Many smaller hospitals face a challenge when urged to both build sophisticated IT infrastructures and control IT costs. The case study has been carried out in the United States and describes the situation in which a regional hospital outsources IT to three rural hospitals. The study design is based on interviews of senior managers from the four hospitals. The results describe benefits such as cost savings, shared IT staff and expertise. Challenges are revealed in areas such as customer service expectations and the complexity of interdependency of relationships between both parties. Lessons learned are discussed and key elements to a successful hospital to hospital partnership are presented. Hospital to hospital partnership proved globally to be satisfactory for both partners if properly managed. 